\title{
Actual Accrual
}

National Cancer Institute

\section{Source}

National Cancer Institute. Actual Accrual. NCI Thesaurus. Code C71471.

A number of subjects that have been enrolled for the participation in a study at a given specified point in time (including all ever-enrolled subjects). 